In another series of experiments we measured contrast sensitivity. The experimenter measured the time that elapsed from the moment the subject passed into darkness to the moment he could distinguish a black silhouette against a dark-grey background. Ten to fifteen experiments on eight subjects led us to conclude that this period is reduced to one half or one third under the influence of light muscular exereise.

What is the physiological mechanism of this influence? We believe that we have here a sensory vegetative reflex, as a result of which the functional state of the retina and, in particular, its absolute and contrast sensitivity, are changed. There are grounds for believing that in such cases the vegetative nervous system also affects the periphery (retina) and the visual centres of the cortex and subcortex of the bemispheres. That it is possible to influence the brain through the vegetative nervous system was demonstrated several years ago by A. V. Tonkikh and E. A. Asratyan in Orbeli's laboratory. A. V. Tonkikh showed this in particular in relation to the spinal cord, and E. A. Asratyan in relation to the cortex of the cerebral hemispheres.

Krikor KeKcheyev.

Soviet Scientists' Anti-Fascist Committee, Moscow. March 19.

1 Bull. Exp. Biol. Med. (1937).

\section{Science or Pseudo-Science}

RECENT discussions on the teaching of science recorded in Nature indicate a wide diversity of opinion and a lack of co-ordinated and constructive suggestion. There is the disconcerting prevalence of self-denunciation among the ranks of science teachers themselves-the admission of 'over-specialization', a predilection to use the term 'humanities' with awe, and a persuasion that a smattering of the facts of all the sciences, pure and applied, is better than a training in scientific procedure. There is also a hankering after the deliberate training of character in the classroom, for example, by 'humanizing' scientific instruction. Smiles on "Character" pricks this bubble in his first few pages. In brief, there are many who contend that unscientific science (that is, science taught and interpreted in the same way as the humanities as factual knowledge) is more desirable than the science advocated by Armstrong, Huxley and Perry.

The teaching of science cannot be discussed in isolation, but only in relation to the whole of education, much of which is out of school. Those who clamour (I think rightly) for the historical method of teaching science should insist that the historian should teach it. History as now taught is political history. The humanities specialize in inhumanityinstruction in the accumulated evil, intrigue, and strife of the ages. Surely, the time has come when the subject-matter of history should be more stimulating and elevating - the history of the progress of mankind (of art, science, industry). General science should be taught by the historian, not by the science master. In the earliest stages English, arithmetic and nature study, if liberally interpreted, provide a complete educational background. Later, nature study gives place to history (including general science and geography).

The Fisher Report (1919) on "The Teaching of English in England" gives an impartial, well-balanced, and searching review of present difficulties in education. Nowhere has the solution of these difficulties been indicated so clearly and convincingly as in this report. Quoting from it:

"Hitherto literature has, even more than science, suffered in the public mind both misunderstanding and degradation. Science has too often been regarded as a kind of skilled labour, a mere handling of materials for profit. Literature has first been confused with the science of language, and then valued for its commercial uses, from the writing of business letters up to the production of saleable books. The word art has been reserved for the more highly coloured or the less seriously valued examples of the latter. We must repeat that a much higher view must be taken of both science and art, and that this view is the only one consistent with a true theory of education. Commercial enterprise may have a legitimate and desirable object in view, but that object cannot claim to be the satisfaction of any of the three great natural affections of the human spirit - the love of truth, the love of beauty, and the love of righteousness."

If English language and literature is made the root and stem of the tree of British education, science can contribute by providing concrete experience for literary and artistic expression. Science is an integration of experience and not of fact. If general science consists of encyclopædic factual knowledge, it is not science, and it cannot be taught as science should be taught. Even special science as now taught in schools is far too much a matter of memory and far too little a matter of experience and scientific development and procedure. The 'specialization' of school science to-day is humanistic specializationan insistence on much fact and little method. At the university, the student is too often 'lectured into a degree'- the natural consequence of early training.

The humanistic specialization of science arises out of an examination system which is almost exclusively a test of factual knowledge and sheer memory. Science syllabuses should be drastically curtailed so that school science deals with fundamentals so exhaustively as to become part and parcel of the student's mental equipment. His knowledge of science should be similar to his knowledge of running and eating. A written examination is quite inadequate and far too precarious as an educational assessment. Fulltime visiting examiners (and advisers) are necessary to assess the work and progress of the pupil and to furnish a detailed record of it.

The primary aim of education should be to create a love of books, a passion for reading, and a desire for knowledge. The pupil must be trained to search for knowledge and to find it. He then educates himself throughout life and stimulates others to do the same. The beginner must not be forcibly fed with classical literature-he must be encouraged to read books that interest him. Any attempt to coerce him is both stupid and dangerous. Post-war houses should be provided with every facility for home education - cupboards, shelving, desks and the equipment for private libraries, studies and laboratories. Education must lead to self-education throughout life. Breadth of vision far transcending anything previously known in education is unlikely but extremely desirable. Small classes, trained and reasonably paid teachers are absolutely essential reforms; also, facilities for adult education-social centres of mental and bodily culture-institutions quite different from a school-halls of leisure). C. W. HANSEL.

Bedford School, Bedford. April 23. 